\title{
Antibiotic resistance profile of local thermophilic Bacillus licheniformis isolated from Maysan province soil
}

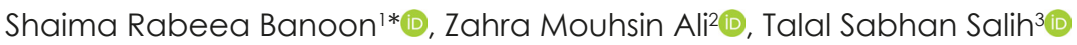 \\ 'Department of Biology, College of Science, University of Misan, Iraq \\ 2Department of Biology, Faculty of Science, University of Kufa, Iraq \\ 'Department of Biophysics, College of Science, University of Mosul, Iraq \\ *Corresponding author, e-mail: shimarb@uomisan.edu.iq
}

\begin{abstract}
The key concern for public health is that bacterial strains isolated from various ecosystems are immune to antibiotics used in human medicine, thus dramatically limiting therapeutic options and threatening the lives of infected people. The present study aims to reveal the antibiotics profile of fiftysix isolates of local thermophilic Bacillus licheniformis isolated from different environmental soil sites in Maysan city, Iraq. The antimicrobial agent resistance profile of $B$. licheniformis isolates was performed using the disc diffusion assay according to KirbyBaver susceptibility test protocol. The results showed that isolates were resistance against cefepime $(n=56$; $100 \%)$, amoxicillin ( $n=13 ; 23.3 \%)$ and ampicillin ( $n=52 ; 92.9 \%)$; and intermediate $(n=56 ; 100 \%)$ against cephalothin and naldixic acid. The percentage resistance was low for aztreonam ( $n=4 ; 7 \%)$, chloramphenicol $(n=3 ; 5 \%)$, clotrimazole $(n=6 ; 10 \%)$, novobiocin $(n=2 ; 3.5 \%)$ and ticarcillin $(n=3 ; 5 \%)$. On the other hand, all isolates were sensitive ( $n=56 ; 100 \%)$ towards the following antibiotics: amikacin, ceftazidime, ciprofloxacin, clindamycin, imipenem, netilmycin, gentamicin, nitrofurantion, rifampin, trimethoprim and vancomycin. The results of this study suggest that the Iraqi thermophilic B. licheniformis isolates are variable in their susceptibility towards the standards antimicrobial agents. Furthermore, the presence of cefepime, amoxicillin, ampicillin, cephalothin and naldixic resistant isolates of $B$. licheniformis in Iraqi soils is of concern about how resistance could spread to other bacteria, and ultimately to humans.
\end{abstract}

Keywords: antibiotic resistance, Bacillus licheniformis, Iraqi soils, Maysan, thermophilic

\section{Introduction}

Bacillus licheniformis named by Weigmann 1898, is a Gram positive facultative, anaerobic, rod shaped and endospore-forming bacterium. The strains of this species are Widely distributed throughout the ecosystem as a saprophytic, where harsh conditions survive in the form of highly resistant endospores and belong to the Bacillus subtilis group (Garrity et al., 2009; Logan \& Vos, 2015). Because of its ability to grow in a thermal environment like a hot spring, the bacterium is known to be facultative thermophilic or thermotolerant microorganism (RodríguezLozano et al., 2010; Fritze, 2004).

It has generation time of $22 \mathrm{~min}$ at $55^{\circ} \mathrm{C}$ compared to $41 \mathrm{~min}$ at $37^{\circ} \mathrm{C}$ (Bischoff et al., 2006). B. licheniformis has been known to produce diverse substances that are useful in industries such as a-amylase, $\beta$-galactosidase, alkaline protease, anti-biofilm, and keratinase (Lin et al., 1992; Declerck et al., 2002; Sellami-Kamoun et al., 2008;
Juajun et al., 2011; Sayem et al., 2011). While generally considered safe, there have been reports of occasional cases of Bacillus licheniformis-associated systemic infections in humans (Santini et al., 1995). However, without prior lesions it has no potential to penetrate the body 's outer barriers. However, abortions in sheep and cattle have been documented, and it has been demonstrated experimentally that Bacillus licheniformis is capable of infecting bovine placenta (Syrjälä et al., 2007; Agerholm et al., 1999).

Reported cases have suggested that lichenysin is produced in most strains of B. licheniformis. Bacillus licheniformis-associated food poisoning lichenysin has been characterized by a relatively short incubation period (2-14h) and a high dose of infection (> 105 $\mathrm{CFUg}^{-1}$ ) accompanied by mild gastrointestinal symptoms lasting 6-24h (Salkinoja-Salonen et al., 1999; Madslien et al., 2013). Lichenysin is an important cyclic lipopeptide against 
the yeast (Noudeh et al., 2010; Kashid \& Ghosh, 2010). Diarrhea is caused by food poisoning, but in half of the confirmed cases, vomiting occurs (Ara et al., 2007). One case of fatal illness associated with infant milk powder infected with Bacillus licheniformis has been reported (Mikkola et al., 2000; Salkinoja-Salonen et al., 1999).

In the past few years, the emergence of antibiotic resistance among bacteria has increased and its possible public health consequences have resulted in enhanced bacterial resistance surveillance in many countries. Bacillus licheniformis strains have received relatively little recognition for their antibiotic resistance; this may be due to their role as non-pathogenic species. Bacilli resistance to various antibiotics has been previously established, and it has been shown that species can be classified in theory on the basis of the results of their susceptibility tests (Reva et al.,1995).

The MIC test for some antibiotics was determined for strains of Bacillus licheniformis which were isolated from starters for the production of Sudanese bread. The MIC test was susceptible to tetracycline (8.0 mg / litre), vancomycin (4.0 mg / litre), and gentamicin (4.0 mg / litre), but was streptomycin resistant (Adimpong et al., 2012). Moreover, disc diffusion assay was reported for antibiotic resistance profiles in the genus of Bacillus particularly for B. cereus (Gao et al., 2018; Fiedler et al., 2019; Park et al., 2020), in contrast very few was reported for B. licheniformis (Jeong et al., 2017; Meneghetti et al., 2018). Because of the limitation of data which is available about the resistance of $B$. licheniformis and to provide a guidance value to clinicians encountering possibly $B$. licheniformis infections; this study was aimed to detect the antibiotic resistance profile of local thermophilic $B$. licheniformis isolated from soil in Maysan Province, Iraq.

\section{Material and Methods}

Fifty six isolates of thermophilic Bacillus licheniformis that isolated and confirmed from the previous study (Banoon \& Ali, 2018) were included in this study. In brief, two grams of soil were added to $10 \mathrm{ml}$ distilled water and mixed well, after a while $0.25 \mathrm{ml}$ from soil suspension was transferred to $25 \mathrm{ml}$ of Lauria broth medium and incubated at $55^{\circ} \mathrm{C}$ for 18 hours. Series of dilutions up to $10^{-3}$ were prepared for each sample. Each dilution was cultured on Lauria agar medium and incubated at $55^{\circ} \mathrm{C}$ for 18 hours. Upon growing, one colony was picked up from fresh overnight agar plates then cultured on a fresh Lauria agar medium and incubated at $65^{\circ} \mathrm{C}$ for confirming the tolerance of high temperatures (as thermophilic).

For the identification of $B$. licheniformis isolates, VITEK-2 compact system using BCL cards and gyrase $B$ gene were used. The antibiotic-resistant of $B$. licheniformis strains was conducted using the disc diffusion method (Baver et al., 1966). A pure culture of B. licheniformis was prepared by adding a growth from an isolated colony to $5 \mathrm{ml}$ of sterile normal saline in a cell density equivalent to McFarland tube turbidity No. (0.5) which is approximately equal to a density of $1.5 \times 10^{8} \mathrm{CFU} / \mathrm{ml}$ of bacterial cells.

A sterile cotton swab was used to Adding -from bacterial suspension to be streaked on Muller-Hinton medium. Twenty seven antibiotic discs (Al-Razi, Iraq) were tested, including amikacin (AMK, $30 \mu \mathrm{g} /$ disc), amoxicillin (AMX, $25 \mu \mathrm{g} /$ disc), amoxicillin-clavulanic acid (AMC, $20 \mu \mathrm{g} / 10 \mu \mathrm{g} /$ disc), ampicillin (AMP, $10 \mu \mathrm{g} /$ disc), aztreonam (ATM, $30 \mu \mathrm{g} /$ disc), cefepime (FEP, $30 \mu \mathrm{g} /$ disc), ceftazidime (CAZ, $30 \mu \mathrm{g} /$ disc), cephalothin (CEF, $30 \mu \mathrm{g}$ / disc), chloramphenicol ( $\mathrm{CHL}, 30 \mu \mathrm{g} /$ disc), ciprofloxacin (CIP, $5 \mu \mathrm{g} /$ disc), clindamycin (CLI, $2 \mu \mathrm{g} /$ disc), clotrimazole (CC, $10 \mu \mathrm{g} /$ disc), erythromycin (ERY, $15 \mu \mathrm{g} /$ disc), gentamicin (GEN, $10 \mu \mathrm{g} /$ disc), imipenem (IPM, $10 \mu \mathrm{g} /$ disc), kanamycin (KAN, $30 \mu \mathrm{g} /$ disc), nalidixic acid (NAL, $30 \mu \mathrm{g} /$ disc), netilmycin (NET, $30 \mu \mathrm{g} /$ disc), nitrofurantoin (NIT, 300 $\mu \mathrm{g} /$ disc), novobiocin (NV, $30 \mu \mathrm{g} /$ disc), oxacillin (OXA, 1 $\mu \mathrm{g} /$ disc), piperacillin (PIP, $100 \mu \mathrm{g} /$ disc), rifampin (RIF, $5 \mu \mathrm{g} /$ disC), ticarcillin (TIC, $75 \mu \mathrm{g} /$ disC), ticarcillin-clavulanic acid (TIM, $75 \mu \mathrm{g} / 10 \mu \mathrm{g} /$ disc ), trimethoprim (TMP, $5 \mu \mathrm{g} /$ disc) and vancomycin (VAN, $30 \mu \mathrm{g} /$ disc). The discs were placed on the surface of the medium at evenly spaced intervals with flaming sterile forceps. The plates were incubated at $37^{\circ} \mathrm{C}$ for $18 \mathrm{hr}$. For each antibiotic the inhibition zone was measured using a ruler.

The presence of a clear zone around the disk has been the index of antibiotic sensitivity. The antibiotic sensitivity test results were determined by the diameter of the inhibition zone (Barry, 1986; Çetin \& Gurler, 1989).

The absence of such a clear zone or the presence of some colonies within the clear zone indicated that the strains collected were resistant to that antibiotic test.

\section{Results and Discussion}

All isolated B. licheniformis strains were tested for their antibiotic resistance against a set of antimicrobial agents using Kirby-Baver disk diffusion method. The Figure (1) showed that all strains were highly sensitive ( $n=56 ; 100 \%$ ) towards the following antibiotics: amikacin, ceftazidime, ciprofloxacin, clindamycin, imipenem, netilmycin, gentamicin, nitrofurantion, rifampin, trimethoprim and vancomycin. However, these results were compatible with studies of (Weber et al., 1988; De Clerck \& De Vos, 2004). In contrast, all isolates showed resistance to cefepime $(n=56 ; 100 \%)$ and intermediate $(n=56 ; 100 \%)$ to cephalothin and naldixic acid. 
Others antibacterial agents were varied in their effects in different ways where the isolates showed resistance against amoxicillin ( $n=13 ; 23.3 \%$ ) and ampicillin $(n=52 ; 92.9 \%)$. Moreover, the results showed that the percentage resistance was low for aztreonam $(n=4$; $7 \%)$, chloramphenicol ( $n=3 ; 5 \%)$, clotrimazole ( $n=6 ; 10 \%)$, novobiocin ( $n=2 ; 3.5 \%)$ and ticarcillin $(n=3 ; 5 \%)$.

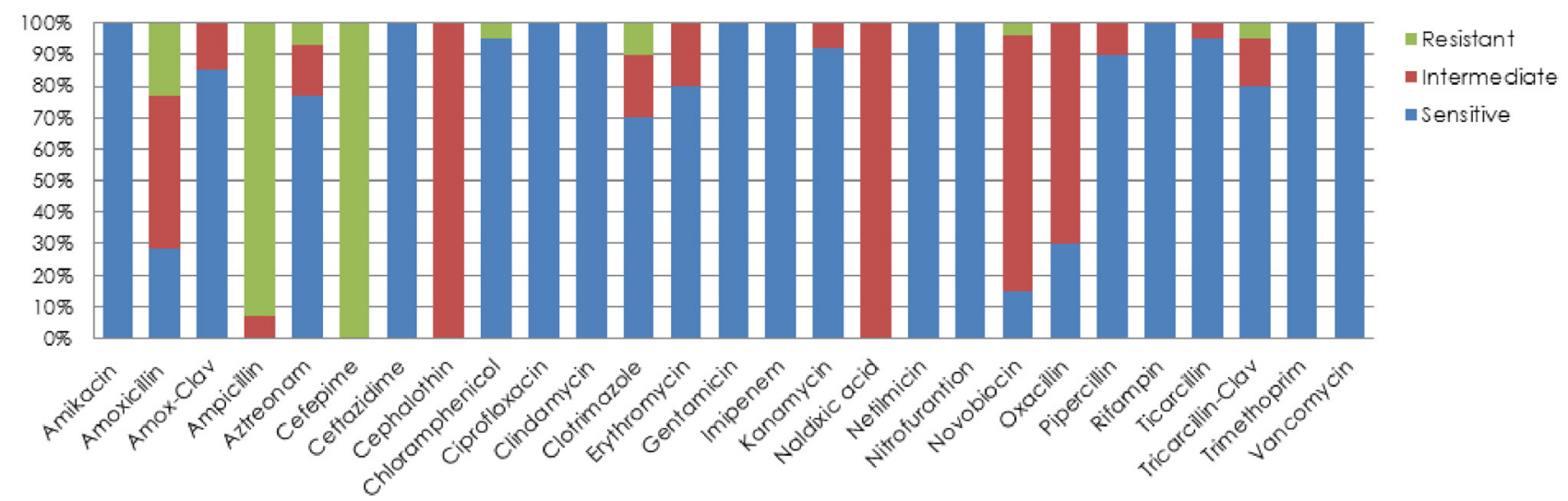

Figure 1. Antibiotic sensitivity profile of Bacillus licheniformis based on inhibition zone diameter (mm); (green) resistance, (red) intermediate, (blue) sensitive.

There are few studies that showed the sensitivity of Bacillus species to antibiotics even though they are related to the genus taxonomy. Banerjee et al., (2007) has noticed that $B$. licheniformis strains were $100 \%$ susceptible to oxytetracycline, gentamicin and chloramphenicol and $40 \%$ were susceptible to bacitracin. Penicillin $G$ has been reported to be less active against $B$. licheniformis (Weber et al., 1988).

A study carried out by Abdel-Shakour \& Roushdy (2010) of Thermo tolerant soil isolate of Bacillus cereus BC2, found that the strain was resistant to the Ampicillin and Amoxycillin while sensitive to the Erythromycin, Amikacin, Chloramphenicol, and Kanamycin. Another study done by Sarker et al., (2010) for Bacillus thuringiensis strains from dump soil showed that the strains were sensitive to erythromycin, chloramphenicol, kanamycin, ampicillin, and vancomycin. On the other hand, when checked by the method of disc diffusion on the nutrient agar plate, the strains showed resistance to amoxicillin, as verified by the method of antibiotic spread plate. Previous studies showed that Vancomycin is bactericidal at or near the same concentration at which it is bacteriostatic (Weber et al., 1988). Almost all strains in our study were resistant to ampicillin ( $n=52 ; 92.9 \%$ ), this was in agreement with a previous study (Andrews \& Wise, 2002).

The Chloramphenicol inhibits protein synthesis by binding to the ribosomal subunit of the 50 s and blocking the peptidyltransferase reaction. By binding to the ribosome and preventing translocation, gentamycin inhibits protein synthesis. Rifampin prevents transcription initiation by binding RNA polymerase to the $B$ subunit of the prokaryotes (Harvey \& Ferrier, 2011).

Kanamycin prevents protein synthesis by binding to and preventing translocation from the ribosomal subunit of the 30s. Timentin is a combination of the penicillin derivative Ticarcillin and the B-lactamase inhibitor, clavulanic acid the exogenous B-lactamase is inactivated by the clavulanic acid, which enables Ticarcillin to prevent the growth of any sensitive cells in the population. Trimethoprim is an inhibitor of the reductase in bacterial dihydrofolic acid (Zähner \& Maas, 1972). In the study carried out by (Ozkocaman et al., 2006), the author showed that $B$. licheniformis isolates were resistant to Clindamycin, penicillin and other B-lactam agents, whilst aztreonam, Imipenem, cefepime, ciprofloxacin, meropenem, levofloxacin, ofloxacin, tetracycline and Vancomycin remained fully active.

A study was done by Bautista \& Teves (2013) for $B$. thuringiensis, which isolated from vermicast a loam soil which considered as non-pathogenic for humans and used extensively for pest control, was found to be resistant to the $\beta$-lactams (amoxicillin and ampicillin). Ampicillin and amoxicillin belong closely to a class of antibiotics called penicillins which are used to treat bacterial infections. Such antibiotics have a common mechanism of action by preventing bacterial cells from multiplying because the walls that surround them are not forming. Although the results of this study have illustrated susceptibility to the most tested antimicrobial agents, several recent studies have been shown increasing in resistance of $B$. licheniformis strains towards antibiotics (Adimpong et al., 2012; Agers $\varnothing$ et al., 2018; Agers $\varnothing$ et al., 2019; Moore et al., 2019).

Cefepime is a broad-spectrum $\beta$-lactam antibiotic that has been introduced in the market for the treatment of serious bacterial infections particularly for the 
treatment of Gram-negative bacteria (Gupta et al., 2006; Donà et al., 2019). Surprisingly, all the isolates in our study were resistant toward cefepime. However, some Grampositive bacteria including Streptococcus pneumoniae, Streptococcus thermophilus, Enterococcus faecium, and Staphylococcus aureus have developed several mechanisms for $\beta$-lactam resistance (Fisher \& Mobashery, 2016; Lemonidis et al., 2019; Aldujaili, \& Banoon, 2020).

In the genus of Bacillus resistance towards $\beta$-lactam antibiotics was also reported. Fenselau et al. (2008) reported that $B$. cereus 5/B line (ATCC 13061) was resistant towards $\beta$-lactam antibiotics. In $B$. licheniformis mechanism of resistance has been observed by the production of BlaP b-lactamase (Vandevenne et al., 2007) and the peptidoglycan fragment that triggers $\beta$-lactam resistance (Amoroso et al., 2012). In addition, the resistance found to cephalothin and nalidixic acid is not surprising as it coincides to what has been found in several studies (Barry \& Jones, 1984; Akinbowale et al., 2006; Crowe-McAuliffe et al., 2018). In a study carried out by Shale \& Malebo (2011), the authors found that $97 \%$ of the $B$. cereus isolates $(n=90)$ were resistant to nalidixic acid.

\section{Conclusion}

The study concludes the high prevalence of $B$. licheniformis and its antibiotic resistance characteristics in Iraqi soils. The resistance of isolates to cefepime, cephalothin, naldixic, amoxicillin, ampicillin, aztreonam, chloramphenicol, clotrimazole, novobiocin and ticarcillin has shown that such antibiotics should not be used in human therapy without prior determination of susceptibility.

Moreover, where the antibiotic resistance of the bacterial strains usually results from chromosome mutations or from the acquisition of resistance plasmids (Inglis, 1999; Balakrishnan et al., 2003), the use of antibiotics for humans needs to be regulated strongly to minimize the opportunity for microorganisms to develop resistance.

\section{References}

Abdel-Shakour, E.H., Roushdy, M.M. 2010. Plasmid Profile and Protease Activity of $\beta$-lactams Resistant Termotolerant Soil Isolate B. cereus BC2 from the Bacillus cereus Group Species. Report and Opinion 2: 82-94.

Adimpong, D.B., Sørensen, K.I., Thorsen, L., Stuer-Lauridsen, B., Abdelgadir, W.S., Nielsen, D.S., Derkx, P.M., Jespersen, L. 2012. Antimicrobial susceptibility of Bacillus strains isolated from primary starters for African traditional bread production and characterization of the bacitracin operon and bacitracin biosynthesis. Applied and Environmental Microbiology 78: 7903-7914.
Agerholm, J.S., Jensen, N.E., Dantzer, V., Jensen, H.E., Aarestrup, F.M. 1999. Experimental infection of pregnant cows with Bacillus licheniformis bacteria. Veterinary pathology 36: 191-201.

Agers $\varnothing$, Y., Bjerre, K., Brockmann, E., Johansen, E., Nielsen, B., Siezen, R., Stuer-Lauridsen, B., Wels, M., Zeidan, A.A. 2019. Putative antibiotic resistance genes present in extant Bacillus licheniformis and Bacillus paralicheniformis strains are probably intrinsic and part of the ancient resistome. Plos one 14: e0210363.

Agers $\varnothing$, Y., Stuer-Lauridsen, B., Bjerre, K., Jensen, M.G., Johansen, E., Bennedsen, M., Brockmann, E., Nielsen, B. 2018. Antimicrobial susceptibility testing and tentative epidemiological cutoff values for five Bacillus species relevant for use as animal feed additives or for plant protection. Applied and Environmental Microbiology 84: e01 108-18.

Akinbowale, O.L., Peng, H., Barton, M.D. 2006. Antimicrobial resistance in bacteria isolated from aquaculture sources in Australia. Journal of Applied Microbiology 100: 11031113.

Amoroso, A., Boudet, J., Berzigotti, S., Duval, V., Teller, N., Mengin-Lecreulx, D., Luxen, A., Simorre, J.P., Joris, B. 2012. A peptidoglycan fragment triggers $\beta$-lactam resistance in Bacillus licheniformis. PLoS pathogens 8: e1002571.

Aldujaili, N.H., Banoon, S.R. 2020. Antibacterial Characterization of Titanium Nanoparticles Nanosynthesized by Streptococcus Thermophilus. Periódico Tchê Química 17: 311-320.

Andrews, J.M., Wise, R. 2002. Susceptibility testing of Bacillus species. Journal of Antimicrobial Chemotherapy 49: 1040-1042.

Ara, K., Ozaki, K., Nakamura, K., Yamane, K., Sekiguchi, J., Ogasawara, N. 2007. Bacillus minimum genome factory: effective utilization of microbial genome information. Biotechnology and Applied Biochemistry 46:169-178.

Balakrishnan, S., John, K.R., George, M.R. 2003. Antibiotic susceptibility of Bacillus spp. isolated from shrimp (Penaeus monodon) culture ponds. Indian Journal of Marine Sciences 32: 81-84.

Banerjee, S., Devaraja, T.N., Shariff, M., Yusoff, F.M. 2007. Comparison of four antibiotics with indigenous marine Bacillus spp. in controlling pathogenic bacteria from shrimp and Artemia. Journal of Fish Diseases 30: 383-389.

Banoon, S.R., Ali, Z.M. 2018. Identification the local thermophilic strains of Bacillus licheniformis by VITEK-2 system and Gyrase B gene. Al-Kufa University Journal for Biology 10:157-167.

Barry, A.L., Jones, R.N., 1984. Cross-resistance among cinoxacin, ciprofloxacin, DJ-6783, enoxacin, nalidixic acid, norfloxacin, and oxolinic acid after in vitro selection of resistant populations. Antimicrobial Agents and Chemotherapy 25: 775-777.

Barry, A.L. 1986. Procedure for testing antimicrobial 
agents in agar media: theoretical considerations. In: Lorian V. Antibiotics in Laboratory Medicine. WilliamsWilkins, Baltimore, London. p. 1-23.

Baver, A.W., Kirby, W.M.M., Sherris, J.C., Turck, M. 1966. Antibiotic susceptibility testing by a standardized single disc method. American Journal of Clinical Pathology 45: 493-496.

Bautista, J.R., Teves, F.G. 2013. Antibiotic susceptibility testing of isolated Bacillus thuringiensis from three soil types around Iligan City, Philippines. African Journal of Microbiology Research 7: 678-682.

Bischoff, K.M., Rooney, A.P., Li, X.L., Liu, S., Hughes, S.R. 2006. Purification and characterization of a family 5 endoglucanase from a moderately thermophilic strain of Bacillus licheniformis. Biotechnology Letters 28:1761-1765.

Çetin, E.T., Gürler, N. 1989. Antibiotic susceptibility tests of bacteria. Kükem Dergisi 2: 97-105.

Crowe-McAuliffe, C., Graf, M., Huter, P., Takada, H., Abdelshahid, M., Nováček, J., Murina, V., Atkinson, G.C., Hauryliuk, V., Wilson, D.N. 2018. Structural basis for antibiotic resistance mediated by the Bacillus subtilis ABCF ATPase VmIR. Proceedings of the National Academy of Sciences 115: 8978-8983.

De Clerck, E., De Vos, P. 2004. Genotypic diversity among Bacillus licheniformis strains from various sources. FEMS microbiology letters 231: 91-98.

Declerck, N., Machius, M., Joyet, P., Wiegand, G., Huber, R., Gaillardin, C. 2002. Engineering the thermostability of Bacillus licheniformis alpha-amylase. BiologiaBratislava 57: 203-212.

Donà, V., Scheidegger, M., Pires, J., Furrer, H., Atkinson, A., Babouee Flury, B. 2019. Gradual In Vitro Evolution of Cefepime Resistance in an ST131 Escherichia coli strain expressing a plasmid-encoded CMY-2 $\beta$-lactamase. Frontiers in Microbiology 10: 1311.

Fenselau, C., Havey, C., Teerakulkittipong, N., Swatkoski, S., Laine, O., Edwards, N. 2008. Identification of $\beta$-Lactamase in Antibiotic-resistant Bacillus cereus spores. Applied and Environmental Microbiology 74(3): 904-906.

Fiedler, G., Schneider, C., Igbinosa, E.O., Kabisch, J., Brinks, E., Becker, B., Stoll, D.A., Cho, G.S., Huch, M., Franz, C.M. 2019. Antibiotics resistance and toxin profiles of Bacillus cereus-group isolates from fresh vegetables from German retail markets. BMC Microbiology 19: 250.

Fisher, J.F., Mobashery, S., 2016. $\beta$-Lactam resistance mechanisms: Gram-positive bacteria and Mycobacterium tuberculosis. Cold Spring Harbor Perspectives in Medicine 6: a025221.

Fritze, D. 2004. Taxonomy of the genus Bacillus and related genera: the aerobic endospore-forming bacteria. Phytopathology 94: 1245-1248.

Gao, T., Ding, Y., Wu, Q., Wang, J., Zhang, J., Yu, S., Yu, P., Liu, C., Kong, L., Feng, Z., Chen, M. 2018. Prevalence, virulence genes, antimicrobial susceptibility, and genetic diversity of Bacillus cereus isolated from pasteurized milk in China. Frontiers in Microbiology 9: 533.

Garrity, G.M., Krieg, N.R., De Vos, P., Jones, D., Ludwig, W., Rainey, F.A., Schleifer, K.H., Whitman, W.B. 2009. Bergey's Manual of Systematic Bacteriology: The Firmicutes. SpringerVerlag, New York, USA. 1449 p.

Gupta, V., Datta, P., Agnihotri, N., Chander, J. 2006. Comparative in vitro activities of seven new beta-lactams, alone and in combination with beta-lactamase inhibitors, against clinical isolates resistant to third generation cephalosporins. Brazilian Journal of Infectious Diseases 10: 22-25.

Harvey, R.A., Ferrier, D.R. 2011. Lippincott's illustrated reviews: Biochemistry. Lippincott Williams \& Wilkins, Philadelphia, Pennsylvania. 551 p.

Inglis, V. 1999. Antibacterial chemotherapy and drug resistance in aquaculture. In: Aquaculture and Biotechnology. Oxford and IBH Publishing Co. Pvt. Ltd., New Delhi, India. p.135-155.

Jeong, D.W., Jeong, M., Lee, J.H. 2017. Antibiotic susceptibilities and characteristics of Bacillus licheniformis isolates from traditional Korean fermented soybean foods. LWT 75: 565-568.

Juajun, O., Nguyen, T.H., Maischberger, T., lqbal, S., Haltrich, D., Yamabhai, M. 2011. Cloning, purification, and characterization of $\beta$-galactosidase from Bacillus licheniformis DSM 13. Applied Microbiology and Biotechnology 89: 645-654.

Kashid, S.G., Ghosh, J.S. 2010. Production, isolation and characterization of exotoxin produced by Bacillus cereus NCIM-2156 and Bacillus licheniformis NCIM-5343. British Journal of Pharmacology and Toxicology 1: 50-55.

Lemonidis, K., Salih, T.S., Dancer, S.J., Hunter, I.S., Tucker, N.P. 2019. Emergence of an Australian-like pstS-null vancomycin resistant Enterococcus faecium clone in Scotland. PloS one 14: e0218185.

Lin, X., Lee, C.G., Casale, E.S., Shih, J.C. 1992. Purification and characterization of a keratinase from a featherdegrading Bacillus licheniformis strain. Applied and Environmental Microbiology 58: 3271-3275.

Logan, N.A., Vos, P.D. 2015. Bacillus. In: Garrity, G.M. Bergey's Manual of Systematics of Archaea and Bacteria. Springer, New York, USA. p.1-163.

Madslien, E.H., Rønning, H.T., Lindbäck, T., Hassel, B., Andersson, M.A., Granum, P.E. 2013. Lichenysin is produced by most B acillus licheniformis strains. Journal of Applied Microbiology 115:1068-1080.

Meneghetti, K.L., do Canto Canabarro, M., Otton, L.M., dos Santos Hain, T., Geimba, M.P., Corção, G. 2018. Bacterial contamination of human skin allografts and antimicrobial resistance: a skin bank problem. BMC Microbiology 18:121.

Mikkola, R., Kolari, M., Andersson, M.A., Helin, J., SalkinojaSalonen, M.S. 2000. Toxic lactonic lipopeptide from food 
poisoning isolates of Bacillus licheniformis. European Journal of Biochemistry 267: 4068-4074.

Moore, R.E., Millar, B.C., Panickar, J.R., Moore, J.E. 2019. Microbiological safety of spices and their interaction with antibiotics: implications for antimicrobial resistance and their role as potential antibiotic adjuncts. Food Quality and Safety 3: 93-97.

Noudeh, G.D., Moshafi, M.H., Kazaeli, P., Akef, F. 2010. Studies on bioemulsifier production by Bacillus licheniformis PTCC 1595. African Journal of Biotechnology 9: 352-356.

Ozkocaman, V., Ozcelik, T., Ali, R., Ozkalemkas, F., Ozkan, A., Ozakin, C., Akalin, H., Ursavas, A., Coskun, F., Ener, B., Tunali, A. 2006. Bacillus spp. among hospitalized patients with haematological malignancies: clinical features, epidemics and outcomes. Journal of Hospital Infection 64:169-176.

Park, K.M., Kim, H.J., Jeong, M., Koo, M. 2020. Enterotoxin Genes, Antibiotic Susceptibility, and Biofilm Formation of Low-Temperature-Tolerant Bacillus cereus Isolated from Green Leaf Lettuce in the Cold Chain. Foods 9: 249.

Reva, O.N., Vyunitskaya, V.A., Reznik, S.R., Kozachko, I.A. and, Smirnov, V.V. 1995. Antibiotic susceptibility as a taxonomic characteristic of the genus Bacillus. International Journal of Systematic and Evolutionary Microbiology 45: 409-411.

Rodríguez-Lozano, A., Campagnoli, M., Jewel, K., Monadjemi, F., Gaze, J.E. 2010. Bacillus spp. thermal resistance and validation in soups. Current Research, Technology and Education Topics in Applied Microbiology and Microbial Biotechnology 1: 537-544.

Salkinoja-Salonen, M.S., Vuorio, R., Andersson, M.A., Kämpfer, P., Andersson, M.C., Honkanen-Buzalski, T., Scoging, A.C. 1999. Toxigenic strains of Bacillus licheniformis related to food poisoning. Applied and Environmental Microbiology 65: 4637-4645.

Santini, F., Borghetti, V., Amalfitano, G., Mazzucco, A. 1995. Bacillus licheniformis prosthetic aortic valve endocarditis. Journal of Clinical Microbiology 33: 30703073.

Sarker, D., Roy, N., Yeasmin, T. 2010. Isolation and antibiotic sensitivity of Bacillus thuringinesis strain from dump soil. Malaysian Journal of Microbiology 6:127-132.

Sayem, S.A., Manzo, E., Ciavatta, L., Tramice, A., Cordone, A., Zanfardino, A., De Felice, M., Varcamonti, M. 2011 . Antibiofilm activity of an exopolysaccharide from a spongeassociated strain of Bacillus licheniformis. Microbial cell Factories 10: 74.

Sellami-Kamoun, A., Haddar, A., Ali, N.E.H., GhorbelFrikha, B., Kanoun, S., Nasri, M. 2008. Stability of thermostable alkaline protease from Bacillus licheniformis RP1 in commercial solid laundry detergent formulations. Microbiological Research 163: 299-306.

Shale, K., Malebo, N.J. 2011 . Quantification and antibiotic susceptibility profiles of Staphylococcus aureus and Bacillus cereus strains isolated from biltong. Journal of
Food Safety 31: 559-569.

Syrjälä, P., Anttila, M., Dillard, K., Fossi, M., Collin, K., Nylund, M., Autio, T. 2007. Causes of bovine abortion, stillbirth and neonatal death in Finland 1999-2006. Acta Veterinaria Scandinavica 49: S3.

Vandevenne, M., Filee, P., Scarafone, N., Cloes, B., Gaspard, G., Yilmaz, N., Dumoulin, M., François, J.M., Frère, J.M., Galleni, M. 2007. The Bacillus licheniformis BlaP $\beta$-lactamase as a model protein scaffold to study the insertion of protein fragments. Protein Science 16: 22602271.

Weber, D.J., Saviteer, S.M., Rutala, W.A., Thomann, C.A. 1988. In vitro susceptibility of Bacillus spp. to selected antimicrobial agents. Antimicrobial Agents and Chemotherapy 32: 642-645.

Zähner, H., Maas, W.K. 1972. The Taxonomic Distribution of Antibiotic-Producing Organisms. In: Biology of Antibiotics. Springer, New York, USA. p. 7-14.

Conflict of Interest Statement: The authors declare that the research was conducted in the absence of any commercial or financial relationships that could be construed as a potential conflict of interest.

All the contents of this journal, except where otherwise noted, is licensed under a Creative Commons Attribution License attribuition-łype BY. 